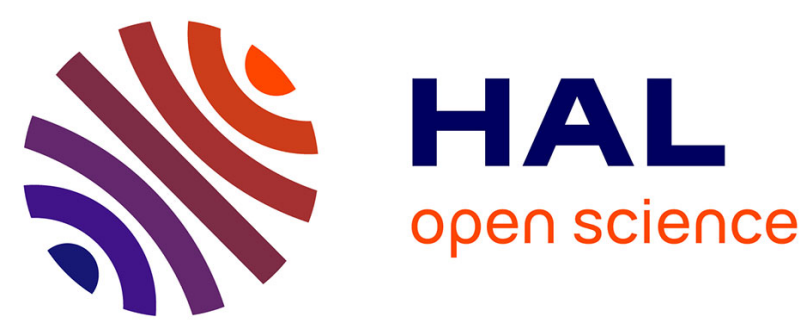

\title{
Interpretation of Electrochemical Impedance for Corrosion of a Coated Silver Film in Terms of a Pore-in-Pore Model
}

\author{
Yasser Ben Amor, Eliane Sutter, Hisasi Takenouti, Mark E. Orazem, Bernard \\ Tribollet
}

\section{To cite this version:}

Yasser Ben Amor, Eliane Sutter, Hisasi Takenouti, Mark E. Orazem, Bernard Tribollet. Interpretation of Electrochemical Impedance for Corrosion of a Coated Silver Film in Terms of a Pore-in-Pore Model. Journal of The Electrochemical Society, 2014, 161 (14), pp.C573-C579. 10.1149/2.1151412jes . hal01080922

\section{HAL Id: hal-01080922 \\ https://hal.sorbonne-universite.fr/hal-01080922}

Submitted on 1 Jul 2015

HAL is a multi-disciplinary open access archive for the deposit and dissemination of scientific research documents, whether they are published or not. The documents may come from teaching and research institutions in France or abroad, or from public or private research centers.
L'archive ouverte pluridisciplinaire HAL, est destinée au dépôt et à la diffusion de documents scientifiques de niveau recherche, publiés ou non, émanant des établissements d'enseignement et de recherche français ou étrangers, des laboratoires publics ou privés. 


\title{
Interpretation of Electrochemical Impedance for Corrosion of a Coated Silver Film in Terms of a Pore-in-Pore Model
}

\author{
Y. Ben Amor ${ }^{\mathrm{a}, \mathrm{b}, \mathrm{c}}$, E.M.M. Sutter ${ }^{\mathrm{a}, \mathrm{b}}$, H. Takenouti ${ }^{\mathrm{a}, \mathrm{b}}$, M. E. Orazem, ${ }^{\mathrm{d}}$ and B. Tribollet ${ }^{\mathrm{a}, \mathrm{b}}$ \\ a Sorbonne Universités, UPMC Univ Paris 06, UMR 8235, Laboratoire Interfaces et \\ SystèmesElectrochimique (LISE), 75252 Paris CEDEX 05, France \\ ${ }^{b}$ CNRS, UMR 8235, LISE, Case 133, 4 place Jussieu, 75252 Paris CEDEX 05, France \\ ${ }^{c}$ Université de Carthage, InstitutSupérieur des Sciences et Technologies de l'Environnement de \\ Borj-Cédria B.P. 1003, Hammam - Lif 2050, Tunisia. \\ ${ }^{d}$ Department of Chemical Engineering, University of Florida, Gainesville, FL 32606 USA
}

Corresponding author: E-mail: yasser_ben@yahoo.fr ; Fax: +216 79325333 


\begin{abstract}
Electrochemical impedance spectroscopy was used to study the degradation behavior of thin multilayer stacks; $\mathrm{Si}_{3} \mathrm{~N}_{4} / \mathrm{Ag} / \mathrm{Si}_{3} \mathrm{~N}_{4}$. Measurements were carried out in $0.5 \mathrm{M} \mathrm{Na}_{2} \mathrm{SO}_{4}$ adjusted at $\mathrm{pH}$ 10. The impedance data collected at the open circuit potential were analyzed with a physical model where all elements are clearly defined. The results suggest a constant phase element behavior at the electrolyte dielectric interface assigned to an in-depth distribution of local resistivity through the dielectric layer induced by the electrolyte penetration. To explain the electrochemical behavior of the thin silver layer, a localized corrosion in a delaminated zone between the upper dielectric and the silver layers was adopted. The localized corrosion was found to be related to the granular structure of the silver layer in which pores are formed between the grains of silver. This model is equivalent to a recently developed double porosity or pore-in-pore model.
\end{abstract}

Keywords: Silver, dielectric, EIS, delamination, double porosity. 


\section{Introduction}

Thin film deposition of metallic, dielectric, and semiconducting materials is widely used in many applications, including microelectronic devices, optical coatings, solar cells, and thin-film batteries [1-4]. Silver is the most used metal for industrial optical applications. This metal possesses the highest reflectivity, from $400 \mathrm{~nm}$ through the IR, and the lowest polarization splitting among all metals [5]. Silver also has the lowest emissivity of all metals in the visible and IR regions. However, in aggressive environments, a silver layer is susceptible to deterioration. This deterioration depends on many factors, such as $\mathrm{pH}$, humidity, temperature, type and concentrations of pollutants, and exposure time. [6-15]

To study the degradation behavior of silver thin films in such environments, different analytical methods are commonly employed. The most commonly used techniques are transmission electron microscopy, atomic force microscopy, and recently time-of-flight secondary ion mass spectrometry [16-17]. These various techniques provide only very local information and often require complex sample preparation. Recently, electrochemical methods, and, more specifically, electrochemical impedance spectroscopy (EIS), have emerged as an alternate way to study material and interface properties of thin film stacks [18-20]. The interpretation of EIS results is usually done through the construction of equivalent electric circuits that simulate the system under investigation. This allows the extraction of physical parameters related to the film microstructure that are not easily accessible by other techniques [21]. For instance, Zeng et al. [18] show that EIS can be applied to measure the nano-porosity of diamond-like carbon films deposited on silicon substrates. They used an equivalent circuit that took into account both open and closed pores. Tse Chu et al. [22] showed that dielectric protected silver reflectors can be reasonably described by an equivalent circuit consisting of two constant phase element (CPE) 
components. They considered only the modulus of the impedance to characterize the electrochemical behavior of the dielectric film. From this model, they proposed a corrosion mechanism for silver through the porous dielectric layer that is similar to models usually quoted in literature [18-21] in which the dielectric layer $\left(\mathrm{SiN}_{\mathrm{x}}\right)$ coating is porous and aggressive agents are able to penetrate the coating and react with silver.

The objective of the present work is to investigate the degradation behavior of a model $\mathrm{Si}_{3} \mathrm{~N}_{4} / \mathrm{Ag} / \mathrm{Si}_{3} \mathrm{~N}_{4}$ stack immersed in alkaline $0.5 \mathrm{M} \mathrm{Na}_{2} \mathrm{SO}_{4}$ solution. Impedance measurements and optical and scanning electron microscopy images are used to formulate a model to describe the electrochemical interaction between the thin silver film and the electrolyte.

\section{Experimental procedure}

The materials, electrochemical techniques, and regression approaches used are presented in this section. The morphology of the thin film sample was examined by optical observation and scanning electron microscopy (SEM).

\subsection{Electrolytes}

Electrolytes were prepared from analytical grade anhydrous sodium sulphate $\left(\mathrm{Na}_{2} \mathrm{SO}_{4}\right)$ and sodium hydroxide $(\mathrm{NaOH})$ dissolved in deionized water. The measurements were performed in a $0.5 \mathrm{M} \mathrm{Na}_{2} \mathrm{SO}_{4}$ electrolyte. The solution $\mathrm{pH}$ was adjusted to a value of 10 by addition of dilute $\mathrm{NaOH}$. The $\mathrm{pH}$ did not change during the course of measurements because the addition of $\mathrm{NaOH}$ at about $1 \times 10^{-4} \mathrm{~mol} \mathrm{~L}^{-1}$ made the solution less sensitive to spontaneous $\mathrm{pH}$ change associated with the dissolution of $\mathrm{CO}_{2}$ gas contained in air. This solution was also used by Y. Wan et al [23] to characterize the corrosion silver products obtained after the ASTM B 117 salt spray corrosion test. 


\subsection{Electrochemical Measurements}

Electrochemical impedance spectra were collected using a Gamry G300 potentiostat. A three electrode cylindrical cell in poly(methyl-methacrylate) was designed for the measurements (Figure 1). A saturated sulphate electrode and a large platinum plate were used for reference and counter electrodes, respectively. To eliminate the experimental artefacts usually observed at high frequency domain $(H F)$ due to the high impedance of the reference electrode, the reference electrode was coupled to a platinum wire in series with a $0.47 \mu \mathrm{F}$ capacitor [24].

\section{$<$ Figure $1>$}

The working electrode was a silver layer embedded between two coatings $\left(\mathrm{Si}_{3} \mathrm{~N}_{4} / \mathrm{Ag} / \mathrm{Si}_{3} \mathrm{~N}_{4}\right)$ upon a silicon substrate $(75 \mathrm{~mm} \times 75 \mathrm{~mm}$ ), as illustrated by the schematic representation in Figure 2. A narrow aluminum tape was thermo-fitted upon the silver layer to ensure electrical contact with the working electrode input of the potentiostat.

\section{$<$ Figure $2>$}

Repeated impedance measurements at the open circuit potential were carried out during $12 \mathrm{~h}$ of immersion after a 1 hour stabilization period. The applied frequency range was from $100 \mathrm{kHz}$ to $10 \mathrm{mHz}$ with 10 points per decade. The amplitude of sinusoidal perturbation was $10 \mathrm{mV}_{\mathrm{rms}}$.

\subsection{Regression}

Experimental spectra were fitted using a simplex procedure by means of an in-house software. The program minimized the $\chi^{2}$ function

$$
\chi^{2}=\sum_{i=1}^{n_{f}}\left[\left(\frac{\hat{Z}_{r}-Z_{r}}{\sigma}\right)^{2}+\left(\frac{\hat{Z}_{j}-Z_{j}}{\sigma}\right)^{2}\right]
$$


where $n_{f}$ is the number of frequencies, the standard deviation for the measurement was assumed to be $\sigma=0.01|Z|$, and the carat refers to the model value. The expression used for $\sigma$ corresponds to an assumption that the standard deviation for the impedance measurement was equal to one percent of the modulus. An improved regression could be obtained by experimental determination of the error structure using, for example, the measurement model concept promoted by Agarwal et al. [25]. This would not have a significant influence on the results reported here because, to a first approximation, the errors obtained under potentiostatic modulation are proportional to the modulus of the impedance. As the weight applied was the same for all regressions, changes in the value of $\chi^{2}$ provide a good indication of the comparative quality of the fit.

For a complex regression, the fitting quality was determined by

$$
q=\sqrt{\frac{x^{2}}{v}}
$$

where $v$ is the degree of freedom for the regression, i.e., the number of observations $2 n_{f}$ minus the number of parameters. A good fit should correspond to a value $q=1$. A smaller value of $q$ means that a priori error was overestimated.

\section{Results and Analysis}

\subsection{Optical and SEM observations}

Ex situ optical and SEM observations were performed on different samples before the measurement and after two different immersion times. Optical and SEM images taken before 
immersion shown in Figure 3 indicate that the structure of the dielectric layer is relatively homogeneous. Before immersion, no structural defects are detected.

$<$ Figures 3 and $4>$

After 3h of immersion, optical and SEM observations (Figs. 4a and 4b) show the presence of two classes of delaminated zones. The first one, identified by optical microscopy (Figure 4 a), corresponds to delamination with a diameter close to $25 \mu \mathrm{m}$. Smaller delamination zones with diameter between 50 and a few hundreds of nm are observed only by SEM (Figure 4b). A similar morphology was observed, even after 12 h of immersion (Figs. 4c and 4d). At an early stage, the solution likely penetrates into the dielectric layer, and silver comes into contact with the solution, but reaches a quasi-steady state before $3 \mathrm{~h}$ of elapsed time. Moreover, the number of large delaminated zones is very small, showing that $0.5 \mathrm{M} \mathrm{Na}_{2} \mathrm{SO}_{4}$ electrolyte at $\mathrm{pH} 10$ is not very aggressive towards the stack.

\subsection{Electrochemical impedance spectroscopy}

\subsubsection{Model of High-Frequency CPE behavior}

Impedance spectra of the working electrode depicted in Figure 2 are presented in Figure 5 in both Nyquist and Bode formats. In the Nyquist plane (Figure 5a), the spectra show a single capacitive loop. The diameter of this loop decreased slightly with immersion time up to $3 \mathrm{~h}$, and then it became practically constant beyond this time. The corresponding Bode plot is presented in Figure 5b. The variation of the impedance modulus $(\log |Z|)$ as a function of frequency $(f)$ shows an inflection point at $0.1 \mathrm{~Hz}$. This inflection seems to indicate the presence of two time constants. The high-frequency time constant can be related to CPE behavior. The impedance of the constant phase element is expressed as 


$$
Z_{\mathrm{CPE}}=\frac{1}{Q(\mathrm{j} \omega)^{\alpha}}
$$

where $Q$ has units of $\mathrm{F} / \mathrm{s}^{1-\alpha} \mathrm{cm}^{2}$ and $\alpha$ is the $C P E$ exponent. The corrosion potential (not shown) was essentially independent of time, indicating that the electrolyte was quickly in contact with the underlying silver metal. The results shown in Figure 5 indicate that the delamination of the $\mathrm{Si}_{3} \mathrm{~N}_{4}$ layer is rapid and then remains unchanged during the remainder of the experiment.

$<$ Figure $5>$

To verify the existence of two time constants, the logarithm of the imaginary part of the impedance, collected for different immersion periods, was plotted with respect to the logarithm of the frequency (Figure 6a). These curves are almost overlapped for different immersion times, and show an apparent linear behavior in the frequency range above $0.1 \mathrm{~Hz}$. The slope $\alpha$ corresponds to the exponent of the CPE.

$<$ Figure $6>$

However, to obtain a more accurate analysis of $\alpha$, the derivatives of these curves were calculated with a moving three-point approximation. As shown in Fig 6b, the CPE behavior with $\alpha$ close to 0.98 was observed in the frequency range between $10 \mathrm{~Hz}$ to $10 \mathrm{kHz}$. Above a frequency of 10 $\mathrm{kHz}$, the calculation of the slope of the line in Figure 6a is sensitive to artifacts, due to the low value of the imaginary part of the impedance. It is important to note that, in the Nyquist diagram, the divergence from linear behavior is only visible below a few tenths of $\mathrm{Hz}$. The value of $\alpha$ decreased to 0.4 at low frequency. Such behavior is often observed in the presence of porous dielectric layers in parallel with a leakage resistance. Therefore, in a first approach, the interface 
between the silver/Si $\mathrm{N}_{4} /$ electrolyte can be represented by the classical equivalent circuit shown in Figure 7 proposed for the first time in reference [26] and used in references [18-22].

$<$ Figure $7>$

The impedance corresponding to the proposed model (Figure 7) can be written as

$$
Z=R_{\mathrm{e}}+\frac{R_{\mathrm{f}}+Z_{\mathrm{i}}}{1+(\mathrm{j} \omega)^{\alpha_{\mathrm{f}}} Q_{\mathrm{f}}\left(R_{\mathrm{f}}+Z_{\mathrm{i}}\right)}
$$

where

$$
R_{\mathrm{f}}=\frac{R_{\mathrm{p}}}{n_{\mathrm{p}}}
$$

is the effective film resistance, $R_{p}(\Omega)$ is the resistance of the electrolyte through a single pore in the dielectric layer, and $n_{p}\left(\mathrm{~cm}^{-2}\right)$ is the number of crossing pores in the dielectric layer per unit surface area. In equation (4), $R_{e}\left(\Omega \mathrm{cm}^{2}\right)$ is the electrolyte resistance, $Z_{i}\left(\Omega \mathrm{cm}^{2}\right)$ is the impedance of the electrolyte / silver interface, and $Q\left(\mathrm{~F} / \mathrm{s}^{1-\alpha} \mathrm{cm}^{2}\right)$ is the CPE coefficient of the dielectric layer.

According to Hirschorn et al. [27], the CPE can be related to a normal distribution of the local resistivity through the dielectric layer. In this case, the local film resistivity is written as [27]

$$
\frac{\rho(\xi)}{\rho_{\delta}}=\left[\frac{\rho_{\delta}}{\rho_{0}}+\left(1-\frac{\rho_{\delta}}{\rho_{0}}\right) \xi^{\gamma}\right]^{-1}
$$

where $\rho_{0}$, assigned a value of $10^{12} \Omega \mathrm{cm}$ [28], and $\rho_{\delta}$ are the boundary values of resistivity at silver / dielectric and dielectric / electrolyte interfaces, respectively; $\xi$ is the dimensionless position, i.e., $\xi=x / \delta$ where $\mathrm{x}$ is the position within the film and $\delta$ is the film thickness ( $\mathrm{x}=0$ at the silver / dielectric interface), and $\gamma$ is a parameter indicating how sharply the resistivity varies. This last parameter is closely related to CPE exponent following

$$
\alpha=\frac{\gamma-1}{\gamma}
$$

The values of the CPE are then correlated to the physical properties of the film according to 


$$
Q_{\mathrm{f}}=\frac{\left(\varepsilon \varepsilon_{0}\right)^{\alpha_{\mathrm{f}}}}{g \delta \rho_{\delta}{ }^{1-\alpha_{\mathrm{f}}}}
$$

where $\varepsilon$ is the dielectric constant of $\mathrm{Si}_{3} \mathrm{~N}_{4}(\varepsilon=7), \varepsilon_{0}$ is the permittivity of vacuum ( $8.84 \times 10^{-14}$ $\mathrm{F} / \mathrm{cm}), \delta$ is the film thickness $\left(20 \times 10^{-7} \mathrm{~cm}\right)$, and $\rho \delta$ is the resistivity of the film at the filmelectrolyte interface.

The properties of the dielectric film were independent of the choice of model for $Z_{i}$. For every case, the fitted CPE parameters were $Q_{f}=4.17 \times 10^{-7} \mathrm{~F} / \mathrm{cm}^{2} \mathrm{~s}^{1-\alpha \mathrm{f}}$ and $\alpha_{\mathrm{f}}=0.98$ (see Tables 1 and 2). The function $g$ is given by equation (28) in reference [27], i.e.,

$$
g=1+2.88\left(1-\alpha_{\mathrm{f}}\right)^{2.375}
$$

and $\rho_{\delta}$ was estimated from Equation (8). The resistivity of the dielectric layer at the interface $\rho_{\delta}$ was found to be approximately $5.3 \times 10^{5} \Omega \mathrm{cm}$.

$$
<\text { Tables } 1 \text { and 2> }
$$

The corresponding resistivity profile, taken from equation (6), is presented in Figure 8. The relationship between resistivity and pore distribution was demonstrated schematically in Figure 1 of Amand et al., [21] where the pore density was assumed to be highest near the film-electrolyte interface and few pores were assumed to extend through the entire dielectric layer. This curve illustrates that the penetration of electrolyte decreasing the film resistivity is limited to the domain close to the electrolyte / dielectric interface ( $\xi>0.75$ ), and, when the resistivity decreases, it follows a power-law distribution.

$<$ Figure $8>$ 


\subsubsection{Determination of $\mathrm{Z}_{\mathrm{i}}$}

Several different models were considered for the interfacial impedance $Z_{i}$. In a first approach, $Z_{i}$. was represented by a charge transfer resistance in parallel with a CPE, which was intended to account for the contribution of a double layer capacitance. Thus,

$$
Z_{\mathrm{i}}=\frac{R_{\mathrm{t}}}{1+(\mathrm{j} \omega)^{\alpha_{\mathrm{d}}} Q_{\mathrm{d}} R_{\mathrm{t}}}
$$

The fitting results are shown in Table 1. The agreement between this model and the experimental data seems to be good in the entire frequency range, and the fitting quality was $q \approx 0.28$. From the experimental data $\left(R_{f}+Z_{i}\right)$ can be obtained by subtracting the contribution of the dielectric response. $\left(R_{f}+Z_{i}\right)$ is represented in Figure 9, and in agreement with the regression the high frequency impedance follows a straight line with a slope 1 .

$<$ Figure 9>

The value of $\alpha_{\mathrm{d}}$ is close to 0.5 , which suggests the limitation by a diffusion process or a porous electrode. As the electrochemical reactions observed by EIS on thick silver films were not influenced by mass transfer [29], the same reactions may be assumed in the present system to be independent of mass transfer. The impedance response was therefore assumed to be associated with a porous electrode. Such behavior has already been described by de Levie [30] in his porous electrode model. Thus, in agreement with the optical observations (Figure 4), localized areas of damage were assumed to consist of a delamination zone at the end of pores (the first model (a) of Tab. 2). A similar behavior was analyzed by Gabrielli et al. [31] in the case of scale deposit. The impedance $Z_{\mathrm{i}}$ was expressed by [30]

$$
Z_{\mathrm{i}}=\frac{1}{n_{1}} \sqrt{R_{1} Z_{1}} \operatorname{coth}\left(L \sqrt{\frac{R_{1}}{Z_{1}}}\right)
$$


where $R_{1}\left(\Omega \mathrm{cm}^{-1}\right)$ is the resistivity of the electrolyte inside a pore of unit length, $n_{1}$ is the number of crossing-pores per unit surface $\left(\mathrm{cm}^{-2}\right), L(\mathrm{~cm})$ is the pore length, and $Z_{1}(\Omega \mathrm{cm})$ is the interfacial impedance for a unit pore length. The interfacial impedance was assumed to follow a $\operatorname{CPE}\left(Q_{\mathrm{d}}\left(\mathrm{F} / \mathrm{s}^{1-\alpha} \mathrm{cm}^{2}\right)\right)$ linked in parallel with a resistance $R_{\mathrm{t}}(\Omega \mathrm{cm})$, i.e.,

$$
Z_{1}=\frac{R_{\mathrm{t}}}{1+(\mathrm{j} \omega)^{\alpha_{\mathrm{d}}} Q_{\mathrm{d}} R_{\mathrm{t}}}
$$

Since $n_{1}$ in Equation (11) is unknown, the electrode impedance was rewritten to avoid interdependent variables. Introduction of equation (12) into equation (11) yields

$$
Z_{\mathrm{i}}=A_{1} \sqrt{\frac{1}{1+(\mathrm{j} \omega)^{\alpha_{\mathrm{d}}} A_{2}}} \operatorname{coth}\left(A_{3} \sqrt{1+(\mathrm{j} \omega)^{\alpha_{\mathrm{d}}} A_{2}}\right)
$$

where

$$
\begin{gathered}
A_{1}=\sqrt{\frac{R_{1} R_{\mathrm{t}}}{n_{1}^{2}}} \quad\left(\Omega \mathrm{cm}^{2}\right) \\
A_{2}=R_{\mathrm{t}} Q_{\mathrm{d}} \quad\left(\mathrm{s}^{\alpha \mathrm{d}}\right)
\end{gathered}
$$

and

$$
A_{3}=\sqrt{\frac{R_{1} L^{2}}{R_{\mathrm{t}}}} \quad \text { (Dimensionless) }
$$

Equations (4) and (13) comprise a model for the experimental system. The fitting parameters are displayed in Table 2 (circuit (a)). The value of exponent $\alpha_{\mathrm{d}}$ is still close to 0.5 indicating that this model still needs improvement. A more complex model was thus devised taking into account the development of pores in the walls of the delaminated zone. This model is equivalent to the secondary pore-in-pore model developed in references 32 and 33. A schematic representation of the corresponding equivalent circuit (circuit (b)) is shown in Table 2. The initial or macropores correspond to the delaminated zone between silver and dielectric layer (see optical and SEM 
observation of Figure 3). The second or meso-porosity, unidentified by the microscopic techniques used, could be related to the grain structure of the silver layer [16-17]. The mesopores may appear, not through the Ag layer, but parallel to its surface, i.e., the delaminated area may have a fern-leaf shape. The given parameters (circuit (b) of Tab. 2) correspond to the fitting data after $12 \mathrm{~h}$ of immersion. According to the de Levie theory, the expression of $Z_{\mathrm{i}}$ becomes

$$
Z_{\mathrm{i}}=\frac{1}{n_{1}} \sqrt{R_{1} \frac{1}{n_{2}} \sqrt{r_{2} Z_{2}}} \operatorname{coth}\left(L \sqrt{\frac{R_{1}}{\frac{1}{n_{2}} \sqrt{r_{2} Z_{2}}}}\right)
$$

In this case: $n_{1}\left(\mathrm{~cm}^{-2}\right)$ and $n_{2}\left(\mathrm{~cm}^{-1}\right)$ are the number of the macropores and the mesopores, respectively, $r_{2}\left(\Omega \mathrm{cm}^{-1}\right)$ is the resistivity of the solution inside the mesoporeper unit length and $Z_{2}(\Omega \mathrm{cm})$ corresponds to the impedance of the charge transfer in the depth of the meso-porosity $(\Omega \mathrm{cm})$. Its expression is similar to that of $Z_{1}$ (see equation (12)). By introducing the expression for $Z_{2}$, equation (17) can be written as

$$
Z_{i}=B_{1} \sqrt{\frac{1}{\sqrt{1+(\mathrm{j} \omega)^{\alpha_{\mathrm{d}}} B_{2}}}} \operatorname{coth}\left(B_{3} \sqrt{\sqrt{1+(\mathrm{j} \omega)^{\alpha_{\mathrm{d}}} B_{2}}}\right)
$$

where

$$
\begin{gathered}
B_{1}=\sqrt{\frac{R_{1} \sqrt{r_{2} R_{\mathrm{t}}}}{n_{1}^{2} n_{2}}}\left(\Omega \mathrm{cm}^{2}\right) \\
B_{2}=R_{\mathrm{t}} Q_{\mathrm{d}} \quad\left(\mathrm{s}^{\alpha_{\mathrm{d}}}\right)
\end{gathered}
$$

and

$$
B_{3}=\sqrt{\frac{n_{2} R_{1} L^{2}}{\sqrt{r_{2} R_{\mathrm{t}}}}} \quad \text { (Dimensionless) }
$$

The value of exponent $\alpha_{\mathrm{d}}$ is 0.87 , which is in the range expected for a surface time-constant distribution. Thus, the progressive model development from an interfacial impedance accounting 
for a faradaic reaction in parallel to a CPE; to a model that accounted for reactions on a porous matrix; to a model that accounted for reactions on pores of different sizes, resulted in a model that yields physically meaningful parameters. The variation of the different double-porositymodel parameters are presented in Figure 10 as a function of immersion time. All values are substantially constant during the entire immersion duration, indicating that the phenomena occurring at the interfaces reach their steady-state rather quickly. The $\mathrm{Na}_{2} \mathrm{SO}_{4}$ solution penetrates into the dielectric layer, and the solution comes into contact with silver from the beginning of immersion. The film resistance determined by pores filling with electrolyte and crossing the dielectric layer $\left(R_{\mathrm{f}}\right)$ is independent of immersion time (Figure 10a).

$<$ Figure 10>

The faradic processes at the silver / electrolyte interface are characterized by the time constant $\left(B_{2}=R_{\mathrm{t}} Q_{\mathrm{d}}\right)$ and the CPE exponent $\alpha_{\mathrm{d}}$ (Figure 10b). The parameter $B_{2}$ remained constant during experiment. Indeed, $Q_{\mathrm{d}}$ is proportional while $R_{\mathrm{t}}$ is inversely proportional to the active surface area. The CPE exponent $\alpha_{\mathrm{d}}$ first increased with immersion time up to $8 \mathrm{~h}$, and then is essentially constant i.e. close to 0.86 . It indicates that the rate of electrolyte penetration is slower in the second porosity than in the dielectric matrix.

\section{Discussion}

The three models presented here for the interfacial impedance provided roughly the same quality of fit to the impedance data. On a Nyquist plot, the fits were indistinguishable. Even the plots of relative regression errors shown in Figure 11 show very little difference between the three models. The R-CPE model shown in Table 1 employed six parameters; whereas, the porous electrode and pore-in-pore model shown in Table 2 each employed seven parameters. The best fit 
was arguably obtained by the R-CPE model. If the goal of the regression is to provide the most parsimonious model for the data, the R-CPE model with the smallest number of parameters and the better fit would be considered the best model.

$<$ Figure 12>

The philosophy of the present work is that the goal of the regression is to provide a quantitative and physical description of the system for which the data were obtained. The R-CPE model yielded both an excellent fit and a CPE exponent with a value of 0.5. But, in this case, the CPE masks the physical meaning of the corresponding impedance. As normal and surface distributions of time constants generally result in CPE exponents between 0.75 and unity, a model yielding $\alpha=$ 0.5 was considered incomplete. The porous electrode model provided a fit that was of about the same quality as the R-CPE model, and the CPE exponent was still on the order of 0.5 . With a slight reduction in the quality of the fit, the pore-in-pore model yielded acceptable values for the CPE exponent and a coherent model for the dissolution process.

\section{Conclusion}

The EIS technique was used to characterize the electrochemical behavior of a silver multilayer stack in $0.5 \mathrm{M} \mathrm{Na}_{2} \mathrm{SO}_{4}$ solution at $\mathrm{pH} 10$. The observed phenomenon was similar to that usually given in the literature: the electrolyte penetrated into the dielectric layer through the pores, which are open at both sides, and comes in contact with silver. Then, a delaminated zone appears and in this zone a localized corrosion occurs. This description corresponds to the double porosity model, based on the de Levie theory. In this case, the two CPE contributions $Q_{\mathrm{f}}$ and $Q_{\mathrm{d}}$ have a clear physical meaning. The first is attributed to a normal distribution of the resistivity through the 
dielectric layer. The second is related to the localized corrosion of the silver layer in the delaminated zone. This model is in good agreement with the experimental results of the present work. 


\section{References}

[1] H. Katagiri, K. Jimbo, S. Yamada, T. Kamimura, W. S. Maw, T. Fukano, T. Ito, T. Motohiro, Enchanced conversion efficiencies of $\mathrm{Cu}_{2} \mathrm{ZnSnS}_{4}$-Based thin film solar cells by using preferential etching technique, Appl. Phys. 1 (2008) 41.

[2] N.J. Dudney, Solid-state thin-film rechargeable batteries, Mater. Sci. Eng., B. 1163 (2005) 245.

[3] D. Minzari, M. S. Jellesen, P. Moller, R. Ambat, Morphological study of silver corrosion in highly aggressivesulfur environments, Eng. Fail. Anal. 18 (2011) 2126.

[4] E. Angelini, S. Grassini, M. Parvis, Silver artefacts: plasma deposition of $\mathrm{SiO}_{\mathrm{x}}$ protective layers and tarnishing evolution assessment, Corrosion Eng. Sci. Tech. 455 (2010) 334.

[5] N. Thomas, A. Erlandson, J. Farmer, H. Gregg, C. Marshall, W. Siekhaus, J. Wolfe, D. Fix, D. Ahre, Laser-Induced Damage in Optical Materials. Proc. SPIE 3578(1998) 730.

[6] I.C. Hamilton, R. Woods, An investigation of the deposition and reaction of sulphur on gold electrode, J. App. Electrochem. 13 (1983) 783.

[7] M. Hepel, S. Bruckenstein, G.C. Tang, The formation and electroreduction of silver sulfide films at a silver metal electrode, J. Electroanal. Chem. 261 (1989), 389.

[8] G. Horanyi, G. Vertes, Radiotracer study of the underpotential formation of a silver sulfide monolayer on silver electrodes in alkaline medium, Electrochim. Acta 31 (1986) 1663.

[9] D.W. Price, G.W. Warren, B. Drouven, The electrochemical behaviour of silver sulphide in sulphuric acid solutions, J. Appl. Electrochem. 16 (1986) 719.

[10] V.I. Birss, G.A. Wright, The potentiodynamic formation and reduction of a silver sulfide monolayer on a silver electrode in aqueous sulfide solutions, Electrochim. Acta 27 (1982) 1. 
[11] C.N.V. Huong, R. Parsons, P. Marcus, Electrochemical behaviour of silver and gold singlecrystal surfaces covered with a monolayer of adsorbed sulphur, J. Electroanal. Chem. 119 (1981) 137.

[12] J.I. Lee, S.M. Howard, J.J. Kellar, W. Cross, K.N. Han, Electrochemical interaction between silver and sulphur in sodium sulfide solutions, Metall. Mater. Trans. A 32B (2001) 895.

[13] T.E. Graedel, Corrosion mechanisms for silver exposed to the atmosphere, J. Electrochem. Soc. 139 (1992) 1963.

[14] S. Bouquet, C. Bodin, C. Fiaud, Influence relative des composéssoufrés et chloréssur le ternissement de l'argent en milieu atmosphérique, C. R. Acad. Sci, Paris t. 316 Série II (1993) 459.

[15] S.J. Nadel, Durability of Ag based low-emissivity, J. Vac. Sci. Technol., A 5 (4) (1987) 2709.

[16] P. Martin, Electrical transport and scattering mechanisms in thin films for thermally insulating glazing, Thesis, Université de Paris VI, (2011).

[17] N. Li, A. Galtayries, I. Frateur, V. Maurice, Corrosion mechanisms of silver thin film in alkaline $\mathrm{Na}_{2} \mathrm{~S}$ solutions, in: European Corrosion Congress 2010, Moscow, Russia 13-17 September 1-4 (2010) 406.

[18] A. Zeng, E. Liu, I.F. Annergren, S.N. Tan, S. Zhang, P. Hing, J. Gao, EIS capacitance diagnosis of nanoporosity effect on the corrosion protection of DLC films, Diamond Relat. Mater. 11 (2002) 160.

[19] L. Paussa, L. Guzman, E. Marin, N. Isomaki, L. Fedrizzi, Protection of silver surfaces against tarnishing by means of alumina/titania-nanolayers, Surf. Coat. Technol. 206 (2011) 976.

[20] M. Lakatos-Varsányi, M. Furko, T. Pozman, Electrochemical impedance spectroscopy study on silver coated metallic implants, Electrochim. Acta 56 (2011) 7787. 
[21] S. Amand, M. Musiani, M.E. Orazem, N. Pébère, B. Tribollet, V. Vivier, Constant-phaseelement behavior caused by inhomogeneous water uptake in anti-corrosion coatings, Electrochim. Acta 87 (2013) 693.

[22] C. Tse Chu, P.D. Fuqua, J.D. Barrie, Corrosion characterization of durable silver coatings by electrochemical impedance spectroscopy and accelerated environmental testing, Appl. Opt. 45 (2006) 1583.

[23] Y. Wan, E.N. Macha, R.G. Kelly, Modification of ASTM B117 salt spray test and its correlation to field measurements of silver corrosion, Corrosion 68 (2012) 36001.

[24] A.T. Tran, F. Huet, K. NgoP. Rousseau, Artefacts in electrochemical impedance measurement in electrolytic solutions due to the reference electrode, Electrochim. Acta 56 (2011) 8034.

[25] P. Agarwal, O. D. Crisalle, M. E. Orazem, L. H. Garcia-Rubio, Measurement Models for Electrochemical Impedance Spectroscopy: 2. Determination of the Stochastic Contribution to the Error Structure, J. Electrochem. Soc., 142 (1995) 4149.

[26] L. Beaunier, I. Epelboin, J.C. Lestrade, H. Takenouti, Etude électrochimique et par microscopieélectronique à balayage du ferrecouvert de peinture, Surface Technology, 4 (1976) 237.

[27] B. Hirschorn, M. E. Orazem, B. Tribollet, V. Vivier, I. Frateur, M. Musiani, Constant-PhaseElement Behavior Caused by Resistivity Distributions in Films: 1. Theory J. Electrochem. Soc., 157 (2010) C452.

[28] Y.G. Gogotsi, Review. Particulate silicon nitride-based composites, J. Mater. Sci. 29 (1994) 2541. 
[29] Y. Ben Amor, E. Sutter, H. Takenouti, B. Tribollet, M. Boinet, R. Faure, J. Balencie, G. Durieu, Electrochemical study of the tarnish layer of silver deposited on glass, Electrochim. Acta, 131 (2014), 89.

[30] R. De Levie, Adv. Electrochem. Electrochem. Eng., Interscience, New York 6 (1967) 329.

[31] C. Gabrielli, M. Keddam, A. Khalil, R. Rosset, M. Zidoune, Study of calcium carbonate scales by electrochemical impedance spectroscopy, Electrochim. Acta, 43 (1997) 1207.

[32] M. Itagaki, Y. Hatada, I. Shitanda, K. Watanabe, Complex impedance spectra of porous electrode with fractal structure, Electrochim. Acta 55 (2010) 6255.

[33] Y. Gourbeyre, B. Tribollet, C. Dagbert, L. Hyspecka, A physical model for anticorrosion behaviour of duplex coatings, J. Electrochem. Soc., 153 (2006) B162. 


\section{Tables caption}

Table 1: Equivalent circuit used for $Z_{\mathrm{i}}$ and values of corresponding fitting parameters

Table 2: Use of the porous electrode model for $\mathrm{Z}_{i}$ (cases of single and double porosity) 
Table 1: Equivalent circuit used for $Z_{\mathrm{i}}$ and values of corresponding fitting parameters

\begin{tabular}{cccccccc}
\hline Equivalent circuit & \multicolumn{6}{c}{ Fitted parameters after12 h of immersion } \\
\hline (a) & $\begin{array}{c}R_{\mathrm{f}} \\
\left(\Omega \mathrm{cm}^{2}\right)\end{array}$ & $\begin{array}{c}Q_{\mathrm{f}} \\
\left(\mathrm{F} \mathrm{cm}^{-2} \mathrm{~s}^{\alpha \mathrm{f}-1}\right)\end{array}$ & $\alpha_{\mathrm{f}}$ & $\begin{array}{c}R_{\mathrm{t}} \\
(\Omega \mathrm{cm})\end{array}$ & $\begin{array}{c}Q_{\mathrm{d}} \\
\left(\mathrm{F} \mathrm{cm}^{-1} \mathrm{~s}^{\alpha \mathrm{d}-1}\right)\end{array}$ & $\alpha_{\mathrm{d}}$ & $q$ \\
\cline { 2 - 8 } & $3.3810^{5}$ & $4.1710^{-7}$ & 0.98 & $6.0110^{7}$ & $1.3210^{-7}$ & 0.51 & 0.28 \\
\hline
\end{tabular}

Table 2: Use of the porous electrode model for $\mathrm{Z}_{i}$ (cases of single and double porosity)

\begin{tabular}{|c|c|c|c|c|c|}
\hline Used model & \multirow{2}{*}{\multicolumn{5}{|c|}{ Fitted parameters after $12 \mathrm{~h}$ of immersion }} \\
\hline \multirow{2}{*}{ (a) single porosity } & & & & & \\
\hline & \multirow{2}{*}{$\begin{array}{c}R_{\mathrm{p}} \\
\left(\Omega \mathrm{cm}^{2}\right)\end{array}$} & \multirow{2}{*}{$\underset{\left(\mathrm{F} \mathrm{cm}^{-2} \mathrm{~s}^{\alpha f-1}\right)}{Q_{\mathrm{f}}}$} & \multirow{2}{*}{$\begin{array}{c}A_{1} \\
\left(\Omega \mathrm{cm}^{2}\right)\end{array}$} & \multirow{2}{*}{$\begin{array}{c}A_{2} \\
\left(\mathrm{~s}^{\alpha \mathrm{d}}\right)\end{array}$} & \multirow[t]{2}{*}{$A_{3}$} \\
\hline $\mathrm{Si}_{3} \mathrm{~N}_{4}$ & & & & & \\
\hline \multirow{3}{*}{ 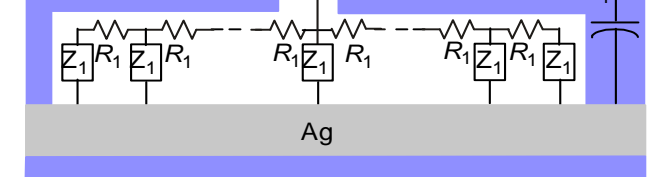 } & $3.0610^{5}$ & $4.1710^{-7}$ & $1.2010^{5}$ & 7.98 & $2.0010^{-3}$ \\
\hline & $\alpha_{\mathrm{f}}$ & $\alpha_{\mathrm{d}}$ & $q$ & & \\
\hline & 0.98 & 0.51 & 0.32 & & \\
\hline \multirow{5}{*}{ 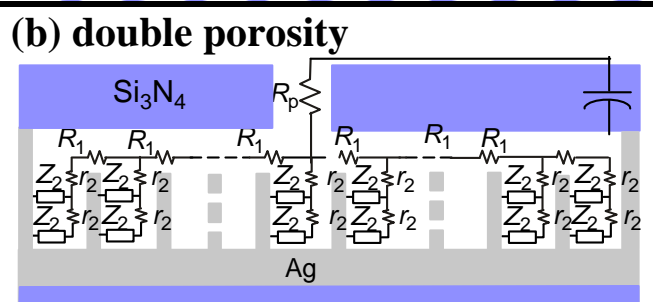 } & $R_{\mathrm{p}}$ & $Q_{\mathrm{f}}$ & $B_{1}$ & $B_{2}$ & $B_{3}$ \\
\hline & $\left(\Omega \mathrm{cm}^{2}\right)$ & $\left(\mathrm{F} \mathrm{cm}^{-2} \mathrm{~s}^{\alpha \mathrm{f}-1}\right)$ & $\left(\Omega \mathrm{cm}^{2}\right)$ & $\left(\mathrm{s}^{\alpha \mathrm{d}}\right)$ & \\
\hline & $3.0610^{5}$ & $4.1710^{-7}$ & $2.1210^{4}$ & 32.40 & $6.0110^{-4}$ \\
\hline & $\alpha_{\mathrm{f}}$ & $\alpha_{\mathrm{d}}$ & $q$ & & \\
\hline & 0.98 & 0.87 & 0.34 & & \\
\hline
\end{tabular}




\section{Figures caption}

Fig. 1: Electrochemical cell.

Fig. 2: Schematic drawing of the stack used as a working electrode.

Fig. 3: Morphology of the surface of the working electrode before measurement: (a) optical characterization, (b) SEM image

Fig. 4: Optical (a, c) and SEM (b, d) images of delamination formed on the surface of the working electrode after two immersion times in $0.5 \mathrm{M} \mathrm{Na}_{2} \mathrm{SO}_{4}$ at $\mathrm{pH}$ 10: (a, b) 3h, (c, d) $12 \mathrm{~h}$. Fig. 5: Impedance spectra recorded at open circuit potential for the working electrode of Fig. 2 in $0.5 \mathrm{M} \mathrm{Na}_{2} \mathrm{SO}_{4}$ at pH 10: (a) Nyquist and (b) Bode plots.

Fig. 6: (a) Representation of the logarithm of the imaginary part of the impedance vs. the logarithm of the frequency, (b) Local slope of curve (a) showing the CPE behaviour and its $\alpha$ value.

Fig. 7: Equivalent electric circuit for the studied interface.

Fig. 8: In-depth profile of the resistivity in dielectric layer calculated from Equation (5).

Fig. 9: The interfacial impedance obtained by subtracting the contribution of the response of the dielectric film.

Fig. 10: Experimental and regressed impedance diagrams for the stack $\mathrm{Si}_{3} \mathrm{~N}_{4} / \mathrm{Ag} / \mathrm{Si}_{3} \mathrm{~N}_{4}$ after $12 \mathrm{~h}$ of immersion in $0.5 \mathrm{M} \mathrm{Na}_{2} \mathrm{SO}_{4}$ at $\mathrm{pH}$ 10. Regression performed with double porosity model.

Fig. 11: Variation of fitted parameters defined by Eqs. (3) and (18) vs. immersion time.

Fig. 12: Regression errors for the three interfacial impedance models employed in the present work. 


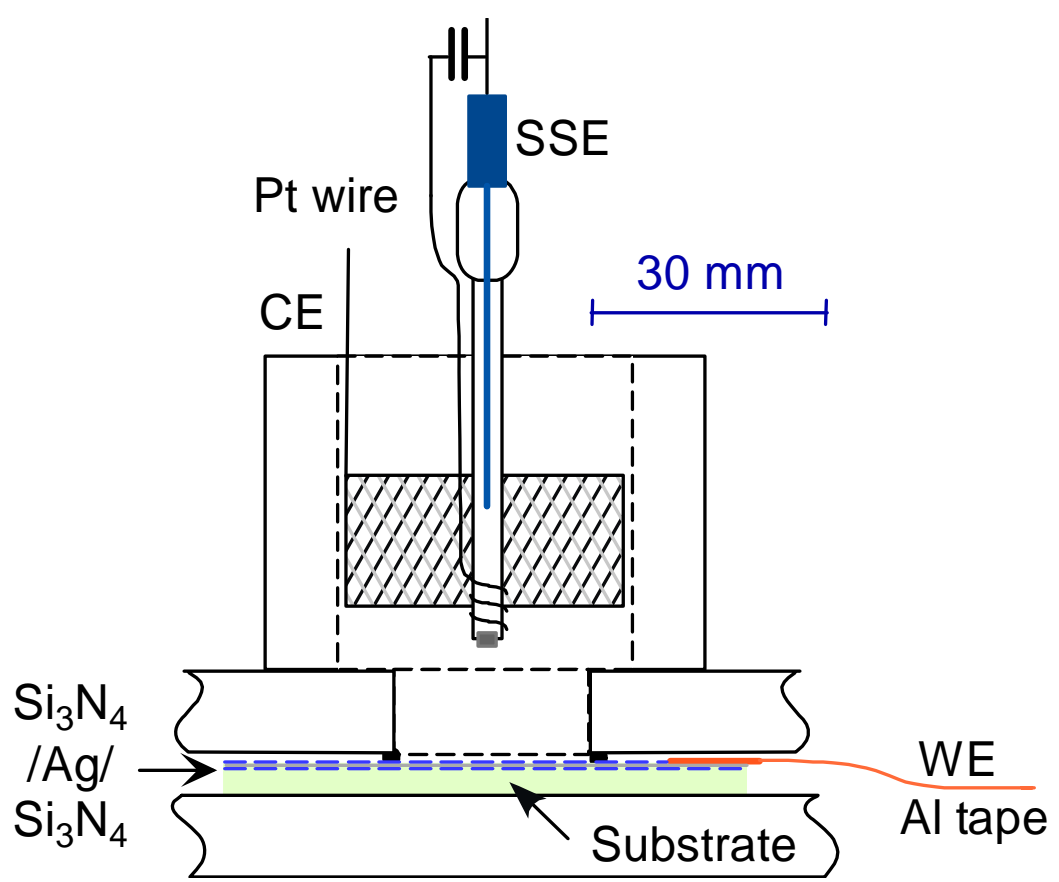

Fig. 1: Electrochemical cell.

$20 \mathrm{~nm} \mathrm{Si}{ }_{3} \mathrm{~N}_{4}$ dielectric layer

$10 \mathrm{~nm} \mathrm{Ag}$

$20 \mathrm{~nm} \mathrm{Si} \mathrm{N}_{4}$ dielectric layer

Substrate

Fig. 2: Schematic drawing of the stack used as a working electrode. 

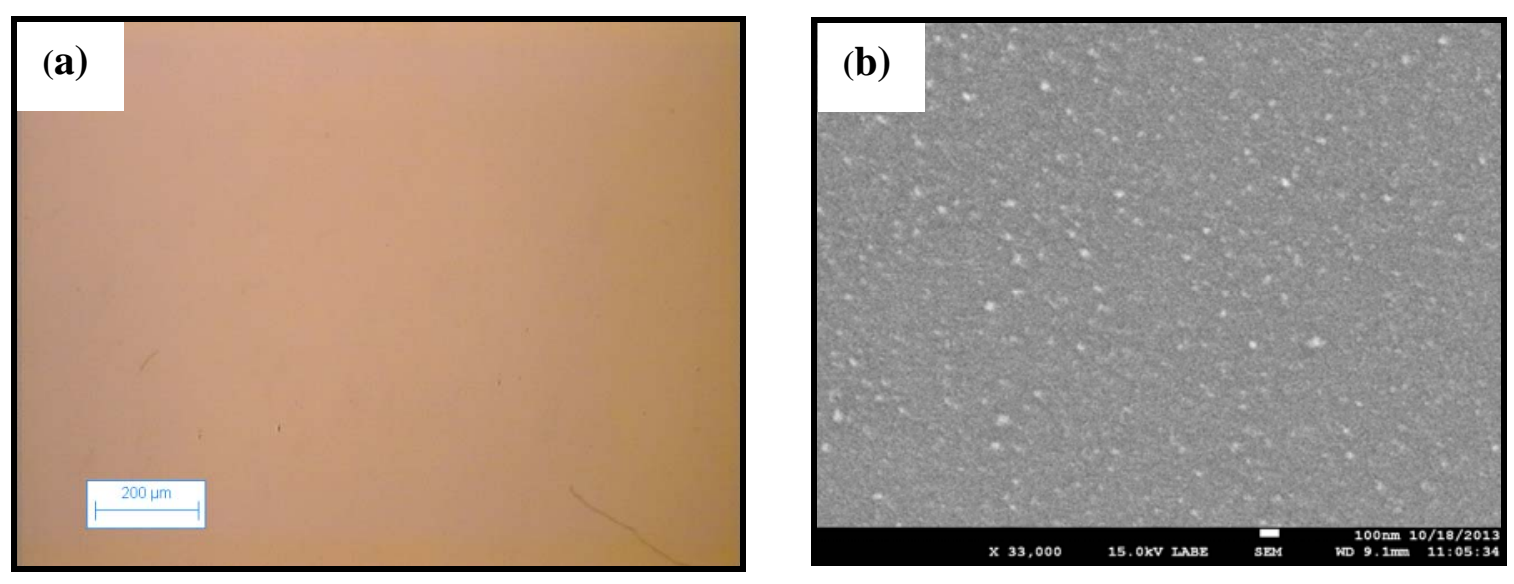

Fig. 3: Morphology of the surface of the working electrode before measurement: (a) optical characterization, (b) SEM image.
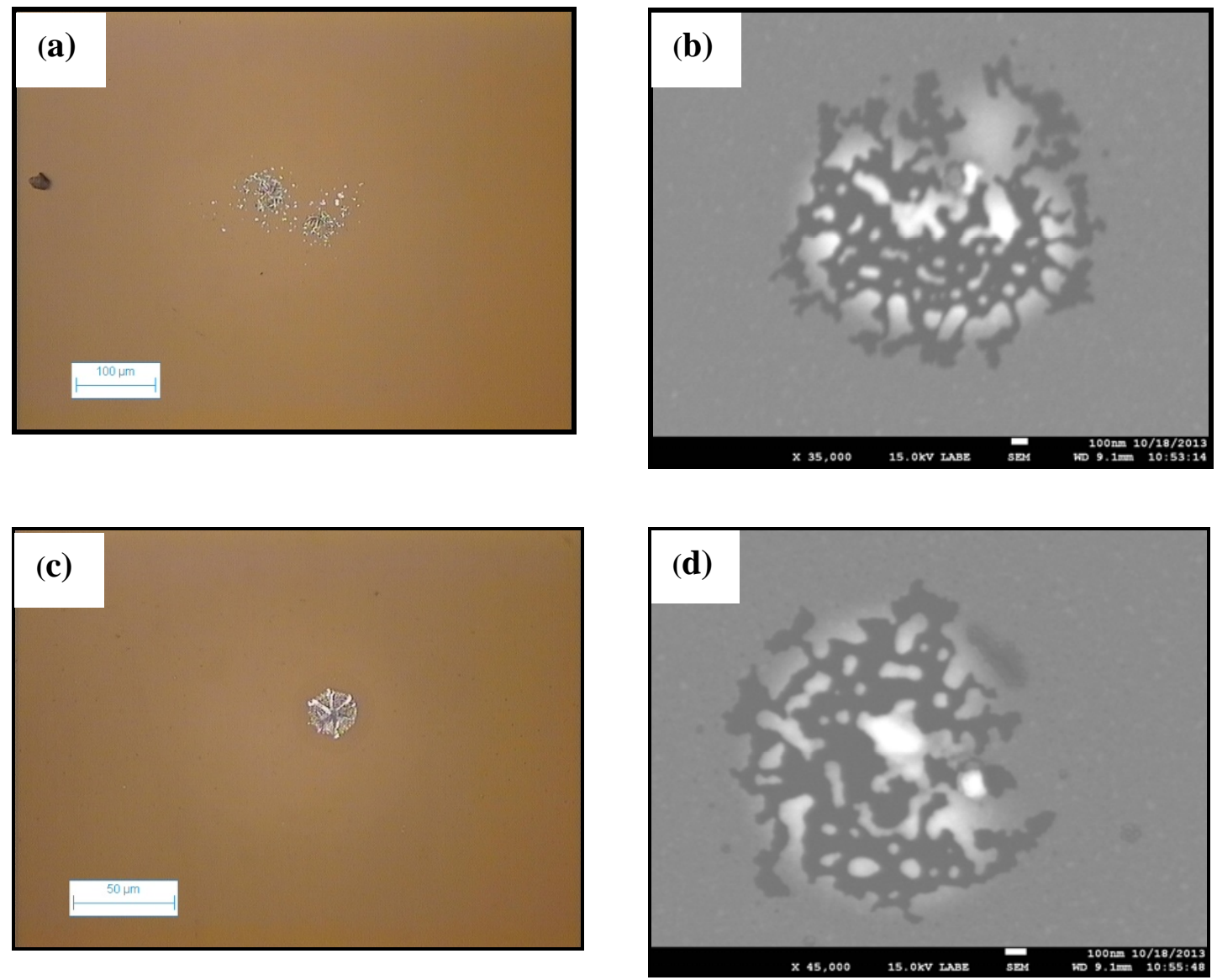

Fig. 4: Optical (a, c) and SEM (b, d) images of delamination formed on the surface of the working electrode after two immersion times in $0.5 \mathrm{M} \mathrm{Na}_{2} \mathrm{SO}_{4}$ at pH 10: (a, b) 3h, (c, d) $12 \mathrm{~h}$. 

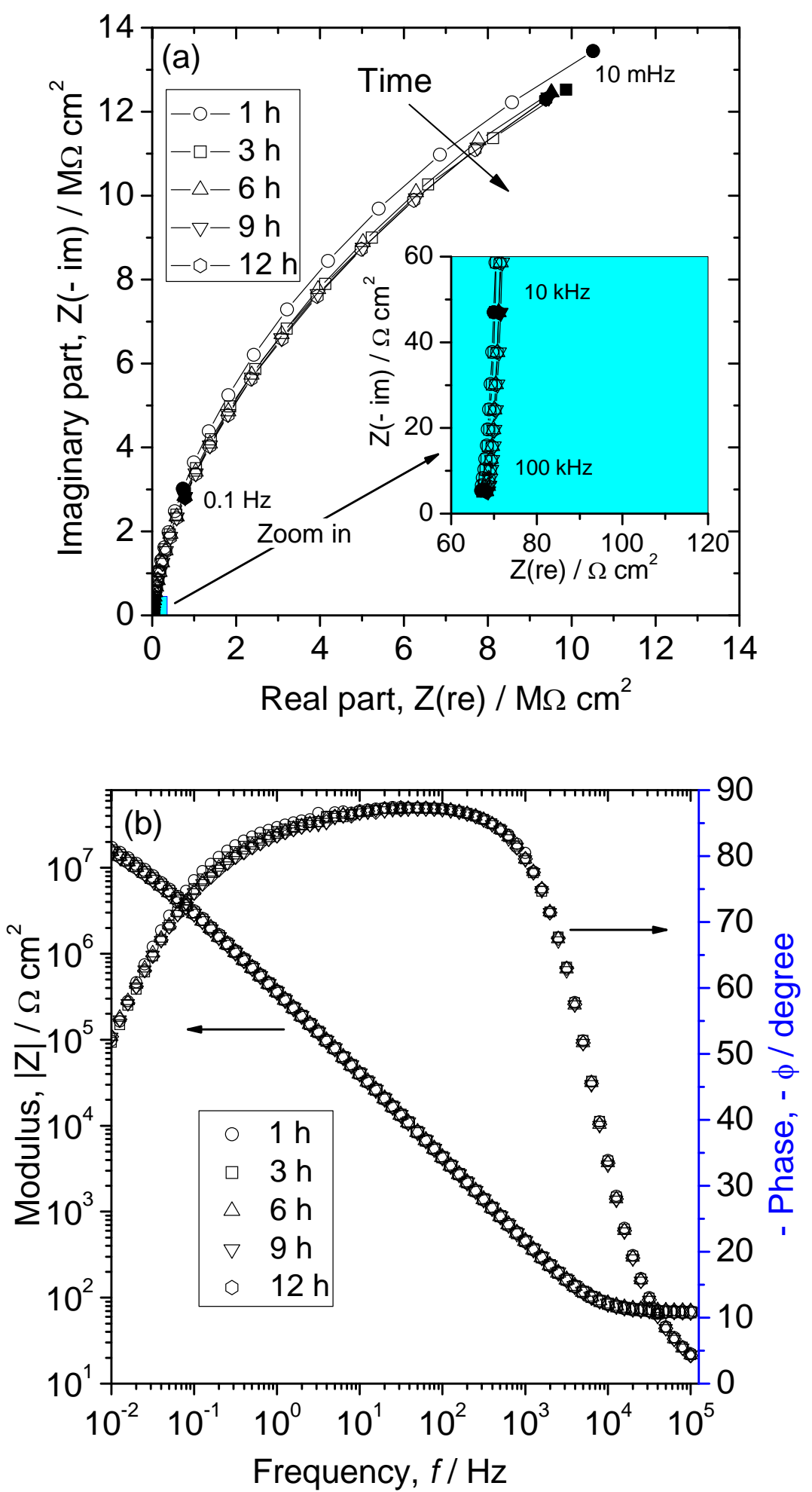

Fig. 5: Impedance spectra recorded at open circuit potential for the working electrode of Fig. 2 in $0.5 \mathrm{M} \mathrm{Na}_{2} \mathrm{SO}_{4}$ at pH 10: (a) Nyquist and (b) Bode plots. 

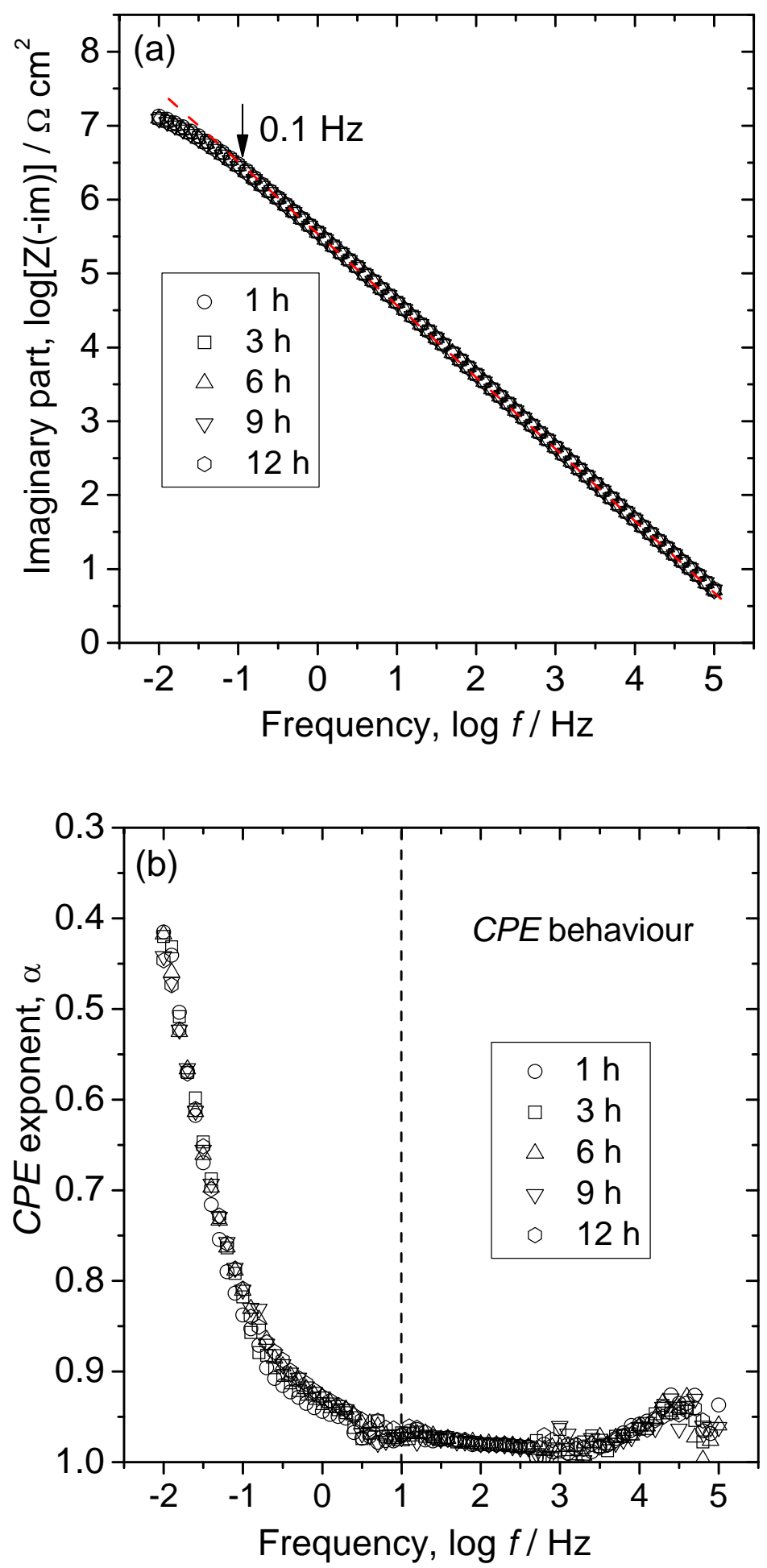

Fig. 6: (a) Representation of the logarithm of the imaginary part of the impedance as a function of the logarithm of the frequency, (b) Local slope of curve (a) showing the $C P E$ behavior and its $\alpha$ value. 


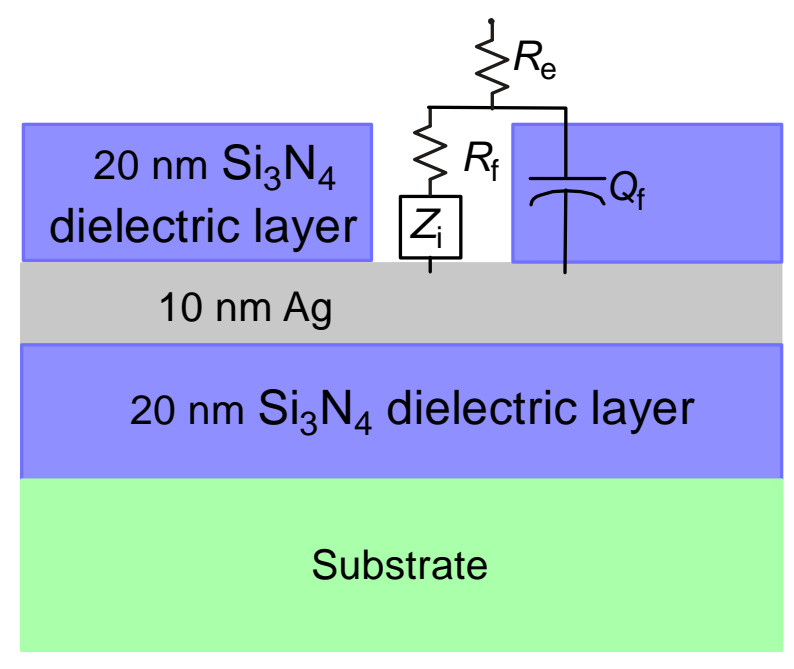

Fig. 7: Equivalent electric circuit for the studied interface.

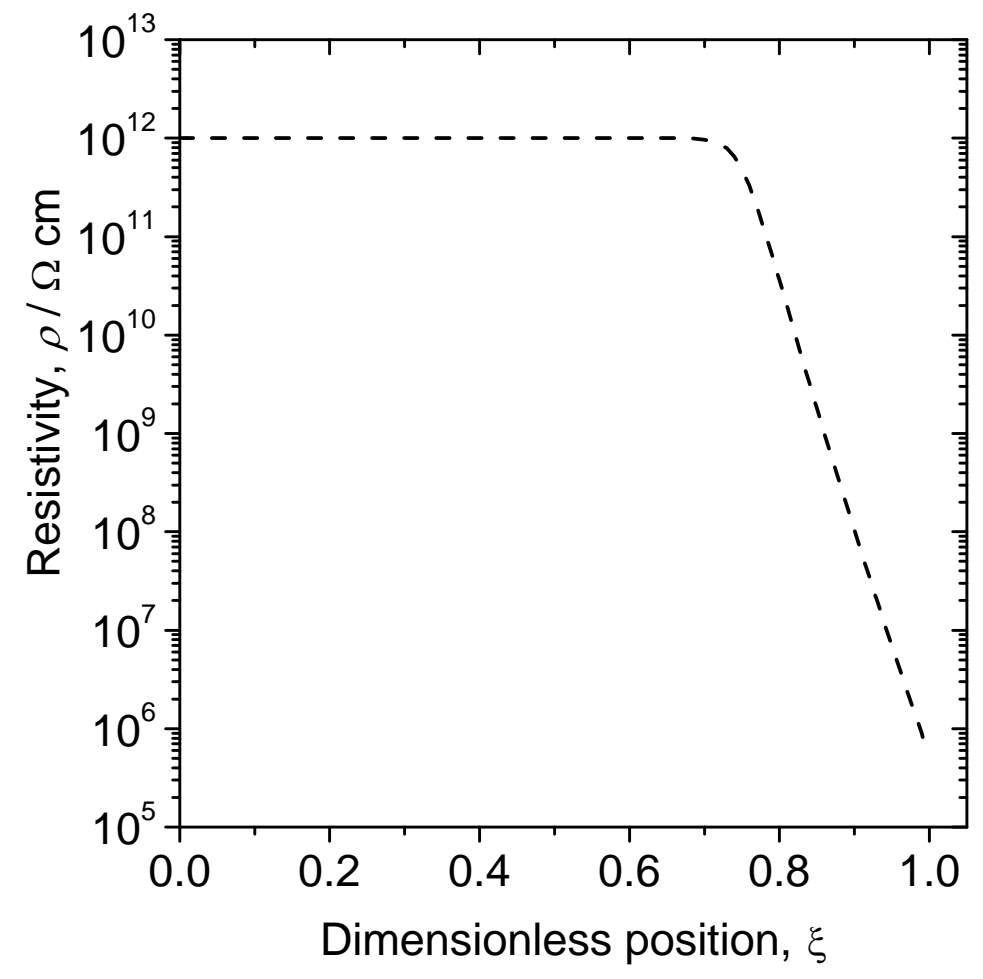

Fig. 8: In-depth profile of the resistivity in dielectric layer calculated from equation (6). 


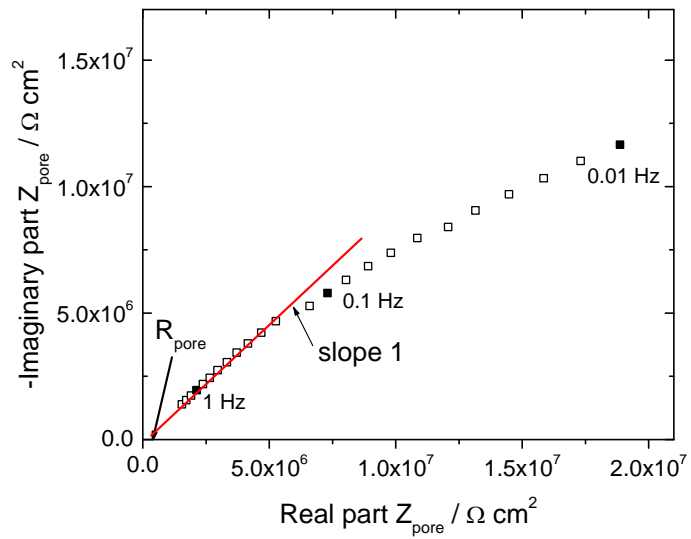

Figure 9. The interfacial impedance obtained by subtracting the contribution of the response of the dielectric film. 


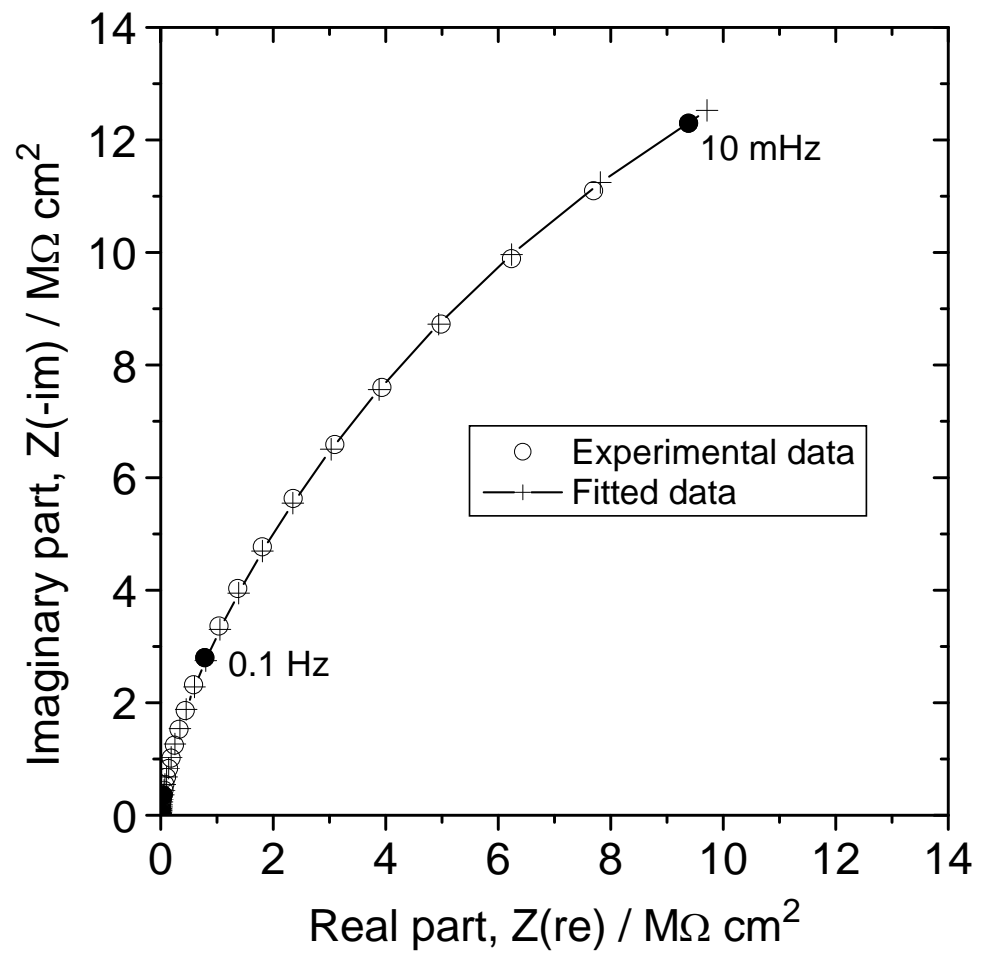

Fig. 10: Experimental and regressed impedance diagrams for the stack $\mathrm{Si}_{3} \mathrm{~N}_{4} / \mathrm{Ag} / \mathrm{Si} \mathrm{i}_{3}$ after $12 \mathrm{~h}$ of immersion in $0.5 \mathrm{M} \mathrm{Na}_{2} \mathrm{SO}_{4}$ at $\mathrm{pH}$ 10. Regression performed with double porosity model. 

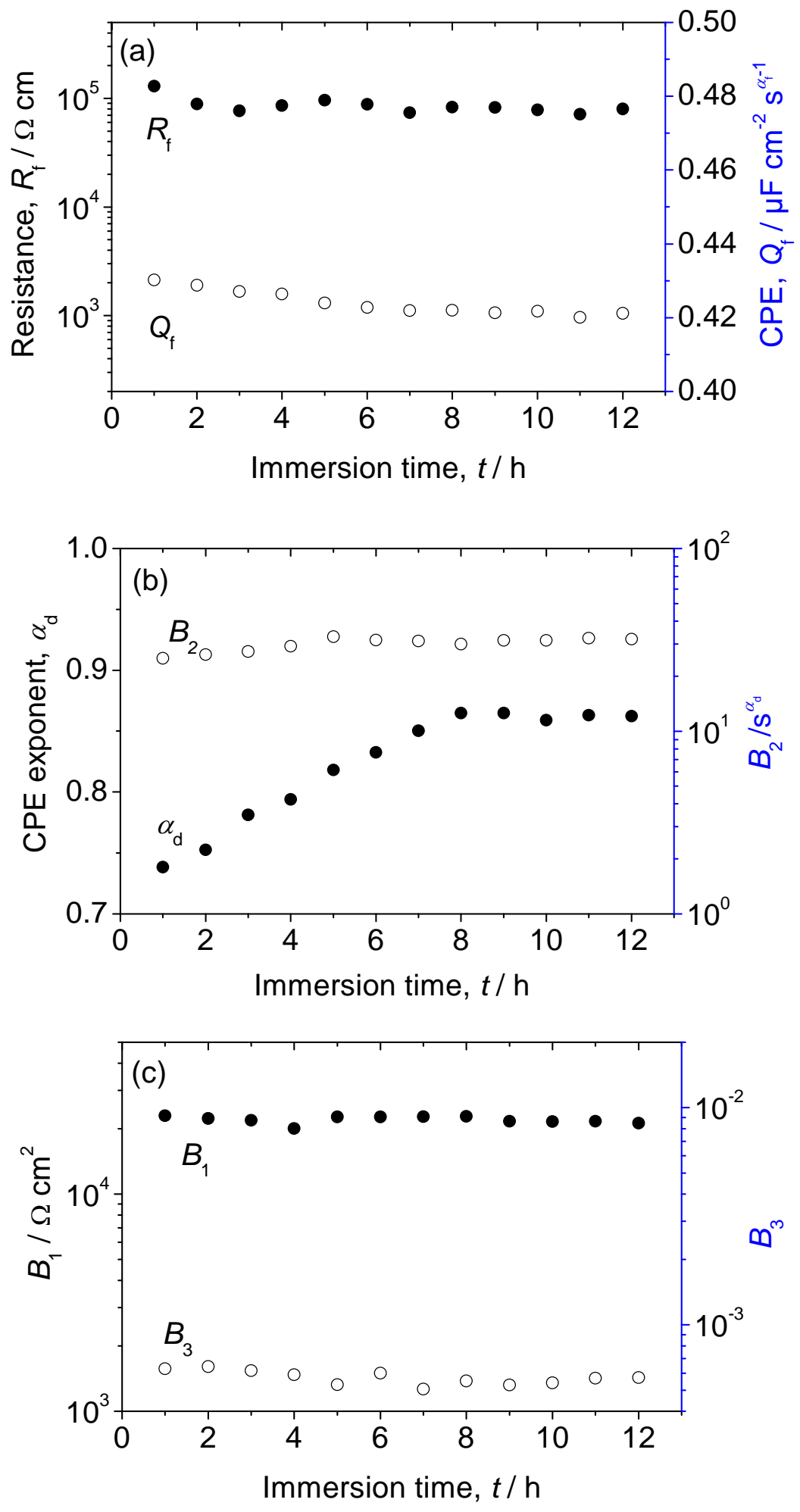

Fig. 11: Variation of fitted parameters defined by equations (4) and (18) vs. immersion time. 

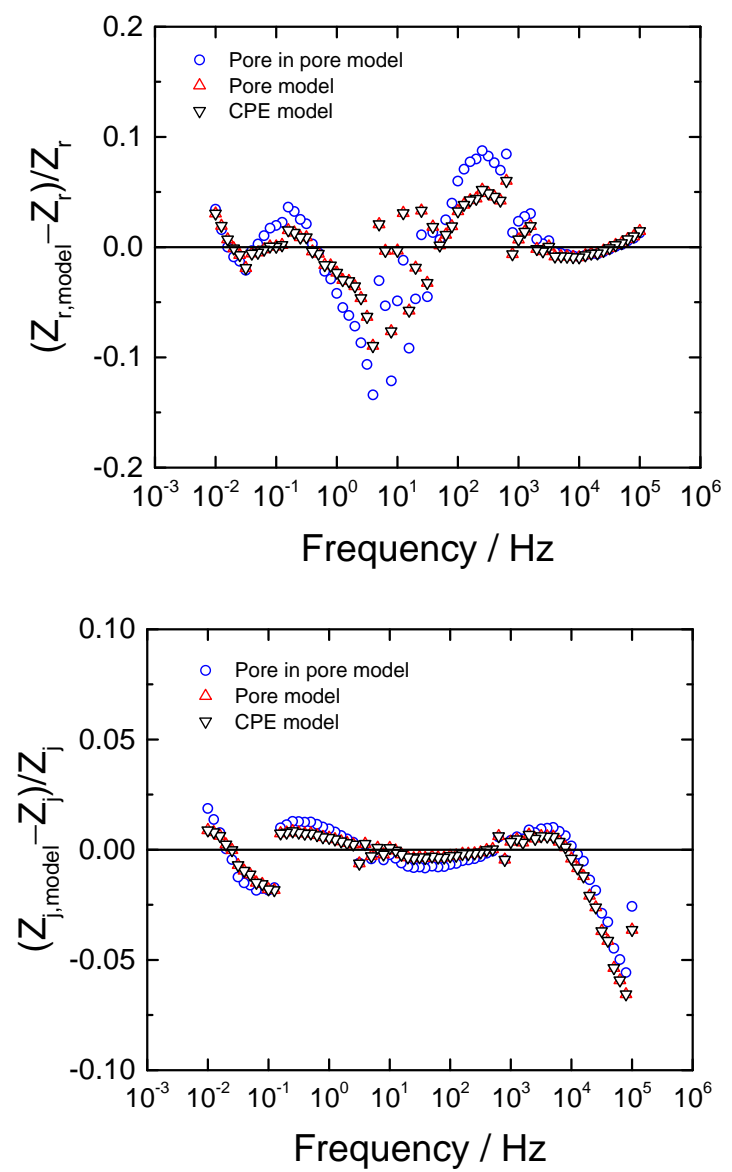

Figure 12. Regression errors for the three interfacial impedance models employed in the present work. 